\title{
Genetic homogeneity of lysinuric protein intolerance
}

\author{
Tuija L auteala ${ }^{1}$, Juha M ykkänen ${ }^{1}$, M aria Pia Sperandeo ${ }^{2}$, Paolo G asparini ${ }^{3}$, M arja-Liisa \\ Savontaus ${ }^{1}$, Olli Simell ${ }^{4}, G_{\text {eneroso A ndria }}^{2}$, G ianfranco Sebastio ${ }^{2}$ and Pentti A ula ${ }^{1}$ \\ ${ }^{1} D$ epartment of M edical G enetics, U niversity of Turku, Finland \\ ${ }^{2} \mathrm{D}$ epartment of Pediatrics, Federico II U niversity, $\mathrm{N}$ aples \\ ${ }^{3}$ I RCCS-CSS H ospital, S G iovanni Rotondo, I taly \\ ${ }^{4} \mathrm{D}$ epartment of Pediatrics, University of Turku, Finland
}

\begin{abstract}
Lysinuric protein intolerance (LPI) is an autosomal recessive disorder in which transport of the cationic amino acids lysine, arginine and ornithine is defective at the basolateral membrane of the epithelial cells in the intestine and renal tubules. LPI is unusually common in Finland, but patients have been described on all continents. Linkage analysis in Finnish LPI families recently assigned the LPI gene locus to a $10 \mathrm{cM}$ interval between markers D14S72 and MYH7 on the long arm of chromosome 14. In the present study linkage analysis of LPI families from six different non-Finnish populations strongly suggests genetic homogeneity in LPI. Peak lod scores were obtained at the chromosomal area between D14S72 and MYH7 with the same markers as in the Finnish families. The non-Finnish families showed no linkage disequilibrium except in an Italian family cluster, whereas strong allelic association in the Finnish families implies that LPI in Finland is caused by a founder mutation.
\end{abstract}

Keywords: genetic homogeneity; lysinuric protein intolerance; linkage analysis; haplotype analysis

\section{Introduction}

Lysinuric protein intolerance (LPI; M IM 222700) is an autosomal recessive disease caused by defective transport of the cationic amino acids lysine, arginine and ornithine at the cell membrane. The main symptoms of LPI are probably secondary to diminished dietary protein tolerance and protein-induced postprandial hyperammonaemia. As a consequence, most patients

Correspondence: Tuija Lauteala, Department of Medical G enetics, U niversity of Turku, K iinamyllynkatu 10, SF-20520 Turku, Finland. Tel: 3582 3337450; Fax: 3582 3337300; E -mail: tuilau@utu.fi

R eceived 26 January 1998; revised 6 M ay 1998; accepted 20 M ay 1998 develop protective aversion to high-protein foods at an early age. ${ }^{1}$ The disease is exceptionally prevalent in the Finnish population. Clusters of LPI families are also known in southern Italy, ${ }^{2}$ where most patients come from the Naples region. Sporadic cases have been described in several other countries.

In Finnish families, we previously assigned the LPI locus to a $10 \mathrm{cM}$ region on chromosome $14 q 11$ between the markers D 14S72 and MYH 7 by linkage analysis. ${ }^{3}$ The wide spectrum of clinical findings in non-Finnish LPI patients, including eg joint hyperextensibility, bone marrow abnormalities, and homocitrullinuria and homoargininuria ${ }^{4,5}$ suggested that genetic heterogeneity in $\mathrm{LPI}$ is possible. We have now evaluated this hypothesis using linkage and haplotype analysis in LPI families 
representing six different non-related, non-Finnish patient populations.

\section{Materials and Methods}

\section{Families}

L inkage was studied in 19 non-Finnish families, of which 13 were Italian, one Swedish, one Latvian, two M oroccan, one Saudi-A rabian and one Turkish. H aplotype analysis included three additional Italian patients, and one Turkish and one E stonian patient. The diagnosis of LPI in all index patients was confirmed by clinical evaluation and by documentation of increased urinary excretion, low plasma concentrations of lysine, arginine and ornithine, and hyperammonemia and/or oroticaciduria after dietary or intravenous nitrogen load.

\section{DNA-marker Analysis}

Genomic DNA was extracted from peripheral blood, from Ebstein-B arr virus-transformed lymphoblast cell lines or from fibroblast cell lines using standard protocols. The polymorphic microsatellite markers D 14S72, D 14S50, D 14S283, TCRA, MYH 7 and D 14S80 were studied in all families. To demonstrate recombination points in I talian families additional microsatellite markers D 14S64, D 14S275, D $14 S 1042$ and TCRD were analysed. PCR for microsatellite markers was performed as described in Lauteala et al. ${ }^{3}$ The amplified fragments were separated by use of $6 \%$ polyacrylamide-7M urea sequencing gels and run and analysed with A BI Prism 377 automatic sequencer.

\section{Statistical Analysis}

Linkage analyses were performed with the LINKAGE program package ${ }^{6}$ using M LINK for pairwise lod scores and GENEHUNTER program package for multipoint analysis. The marker order and distances were based on combined CEPH -LPI data ${ }^{3}$ and G énéthon microsatellite marker map. ${ }^{8}$ The heterogeneity test was done with the MTEST program from the HOMOG program package. ${ }^{9}$

\section{Results}

In pairwise linkage analysis performed with microsatellite markers in 19 non-Finnish LPI families with 24 affected individuals and 51 family members ( 13 families came from I taly), highest lod scores were obtained with the markers D 14S50, TCRA and D 14S283, with maximum lod scores of 4.37, 4.04 and 3.57, respectively, at $\theta=0$ (Table 1). No recombinations were found between these three markers and the LPI locus, whereas marker D $14 S 72$ showed recombinations in one I talian family and marker MYH 7 in one Italian, one Swedish and one Saudi-A rabian family. Seven-point linkage analysis between LPI and the markers D 14S72, D 14S50, D 14S283, TCR A , M Y H 7 and D $14 S 80$ gave the highest lod score of 7.36 and the corresponding map
Table 1 Pairwise lod scores between LPI and six marker loci in non-Finnish LPI families

\begin{tabular}{lllllll}
\hline M arker & \multicolumn{6}{l}{ L od score at $\theta=$} \\
\cline { 2 - 5 } L ocus & 0.00 & 0.001 & 0.01 & 0.05 & 0.10 & $Z_{\text {max }}$ \\
\hline D 14S72 & $-\infty$ & 2.83 & 3.69 & 3.75 & 3.23 & 3.85 \\
D 14S50 & 4.37 & 4.36 & 4.25 & 3.73 & 3.04 & 4.37 \\
D 14S283 & 3.57 & 3.56 & 3.47 & 3.03 & 2.46 & 3.57 \\
T CR A & 4.04 & 4.04 & 4.02 & 3.70 & 3.14 & 4.04 \\
M Y H 7 & $-\infty$ & -3.91 & -0.72 & 1.36 & 1.78 & 1.79 \\
D 14S80 & $-\infty$ & 0.24 & 2.10 & 2.84 & 2.64 & 2.84 \\
\hline
\end{tabular}

location was $3.92 \mathrm{~cm}$ telomeric from the marker D 14572 (Figure 1).

When the Italian families were analysed separately from the other non-Finnish families, slightly different results were obtained. The highest lod score of 3.08 was again obtained with the marker D14S50, whereas D 14S283 and TCRA gave lod scores of 2.41 and 2.51, respectively, but in addition the marker D14S80 (located $10 \mathrm{~cm}$ telomeric from the framework marker MYH 7), ${ }^{8}$ also had a high lod score of 2.87. The multipoint linkage curve, however, displayed a peak at the cluster of D14S50, D 14S283 and TCRA. We also generated haplotypes in Italian families with additional markers flanking D 14580 and demonstrated a recombination in one family between MYH 7 and the marker

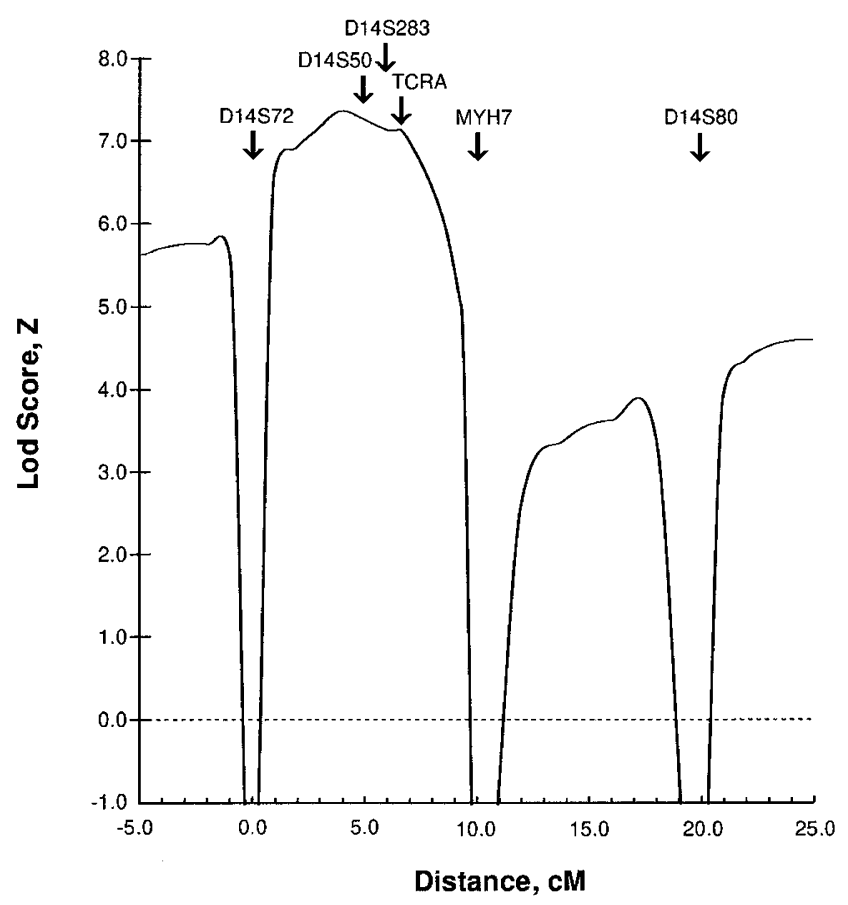

Figure 1 Seven point linkage analysis between L PI locus and six marker loci. The family data include 19 non-Finnish L PI families. 
D 14S64, which is located between MY H 7 and D 14 S80. This restricts the critical region of the L PI gene also in the Italian families to the area between D 14S72 and MY H 7. The marker D 14580 revealed in our 20 Finnish LPI-families four recombination events, and two additional recombination events were even found in the non-Finnish, non-I talian families. 0 ur results thus give no evidence of locus heterogeneity in LPI $\left(\chi^{2}=3.73\right.$; $P>0.05)$.

We previously found strong linkage disequilibrium in Finnish families between LPI locus and several markers on the $5.1 \mathrm{cM}$ region between D $14 S 742$ and MYH 7. In the non-Finnish families shared haplotypes were seen only in the four I talian families originating from a small village near Naples. The 6-1 haplotype (D 14S283, TCRA ) was present in seven out of ten chromosomes from this subgroup of patients (Figure 2, lines 1 to 7 from the top). The Italian families, considering together, showed no common haplotypes and $P_{\text {excess }}$ value of the best marker D 14S283 was only 0.39 ( $P$ excess was calculated as described in Lauteala et al. ${ }^{3}$ ) In addition two Italian patients shared the haplotype 6-4-13 (D 14S283, TCRA and MYH 7) that showed strong linkage disequilibrium in the Finnish LPI chromosomes. Swedish, Estonian and Lithuanian patients shared the TCRA allele 4.

\section{Discussion}

Two point linkage analysis in 19 non-Finnish LPI families gave positive lod scores on the proximal long arm of chromosome 14 with the same markers as were previously observed in the Finnish families. Such data strongly suggests genetic homogeneity in LPI. The peak lod scores in the non-Finnish families were obtained with the markers D14S283 and TCRA which also display the strongest linkage disequilibrium in the Finnish LPI chromosomes. The critical gene region, spanning a $10 \mathrm{cM}$ interval at $14 q 11$, was defined in nonFinnish families by recombinations with the markers D $14 S 72$ and M Y H 7, similarly to what was found in the Finnish families. The I talian families had relatively high lod scores also with the marker D 14S80, which is located $10 \mathrm{cM}$ distally from TCR A. H owever, extended haplotypes of the Italian families revealed that the critical region is between D $14 S 72$ and MY H 7. Genetic homogeneity between the Finnish and Italian LPI patients was also confirmed by the M TEST computer program.
A llelic association was found in four of five Italian families that originated from a small village near $\mathrm{N}$ aples, but not in the rest of I talian LPI chromosomes nor in the whole group of the non-Finnish families. The subgroup of LPI families which showed allelic association probably shares a common founder mutation.

\begin{tabular}{|c|c|c|c|c|c|c|c|c|c|}
\hline Nationality & D14S7: & & D14S50 & & D14S28: & & TCRA & & MYH7 \\
\hline \multirow[b]{2}{*}{ Italian } & 3 & - & 6 & 4 & 6 & +3 & 1 & - & 12 \\
\hline & $\left\{\begin{array}{l}3 \\
3\end{array}\right.$ & - & 6 & - & 6 & $\rightarrow$ & 1. & - & 12 \\
\hline \multirow{2}{*}{ Italian } & $\int 3$ & - & 6 & - & 6 & 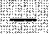 & 1 & - & 12 \\
\hline & 8 & - & 6 & - & 6 & - & 1 & - & 12 \\
\hline \multirow{2}{*}{ Italian } & 3 & - & 6 & $=$ & 6 & - & 1. & $\rightarrow$ & 12 \\
\hline & 2 & - & 6 & + & 6 & - & 1 & - & 12 \\
\hline \multirow{2}{*}{ Italian } & 3 & - & 8 & - & 6 & $\rightarrow$ & 1) & - & 13 \\
\hline & 3 & - & 3 & - & 1 & - & 3 & - & 12 \\
\hline \multirow{2}{*}{ Italian } & 7 & - & 4 & - & 2 & - & 9 & - & 11 \\
\hline & 7 & - & 4 & - & 2 & - & 9 & - & 11 \\
\hline \multirow{2}{*}{ Italian } & 8 & - & 6 & - & 2 & - & 2 & - & 6 \\
\hline & 8 & - & 4 & - & 8 & - & 2 & - & 6 \\
\hline \multirow{2}{*}{ Italian } & 3 & - & 4 & - & 2 & - & 1 & - & 13 \\
\hline & 3 & - & 4 & - & 2 & - & 1 & - & 5 \\
\hline \multirow{2}{*}{ Italian } & 3 & - & 4 & - & 2 & - & 1 & - & 13 \\
\hline & 3 & - & 4 & - & 2 & - & 1 & - & 13 \\
\hline \multirow{2}{*}{ Italian } & 3 & - & 6 & - & 2 & - & 1 & - & 14 \\
\hline & 3 & - & 6 & - & 2 & - & 1 & - & 14 \\
\hline \multirow{2}{*}{ Italian } & 2 & - & 4 & - & 2 & - & 2 & - & 11 \\
\hline & 2 & - & 4 & - & 2 & - & 2 & - & 11 \\
\hline \multirow{2}{*}{ Italian } & 1 & - & 2 & - & 6 & - & 4 & - & 13 \\
\hline & 1 & - & 2 & - & 6 & - & 4 & - & 13 \\
\hline \multirow{2}{*}{ Italian } & 8 & - & 7 & - & 1 & - & 1 & - & 13 \\
\hline & 4 & - & 7 & - & 2 & - & 1 & - & 13 \\
\hline \multirow{2}{*}{ Italian } & 8 & - & 6 & - & 6 & - & 9 & - & 6 \\
\hline & 6 & - & 3 & - & 2 & - & 2 & - & 6 \\
\hline \multirow{2}{*}{ Italian } & 6 & - & 4 & - & 3 & - & 4 & - & 13 \\
\hline & 3 & - & 6 & - & 2 & - & 9 & - & 13 \\
\hline \multirow{2}{*}{ Italian } & 3 & - & 6 & - & 6 & - & 4 & - & 13 \\
\hline & 2 & - & 4 & - & 6 & - & 4 & - & 13 \\
\hline \multirow{2}{*}{ Italian } & 2 & - & 5 & - & 6 & - & 9 & - & 13 \\
\hline & 2 & - & 5 & - & 6 & - & 9 & 一 & 12 \\
\hline \multirow{2}{*}{ Estonian } & 2 & - & 4 & - & 2 & - & 1 & - & 15 \\
\hline & 9 & - & 4 & - & 3 & - & 4 & - & 13 \\
\hline \multirow{2}{*}{ Lithuanian } & 2 & - & 5 & - & 3 & - & 4 & - & 12 \\
\hline & 6 & 一 & 5 & - & 3 & - & 4 & - & 12 \\
\hline \multirow{2}{*}{ Swedish } & 3 & - & 6 & - & 5 & 一 & 4 & - & 13 \\
\hline & 3 & - & 6 & - & 5 & - & 4 & - & 13 \\
\hline \multirow{2}{*}{ Saudi-Arabian } & 7 & - & 6 & - & 6 & - & 1 & 一 & 12 \\
\hline & 9 & - & 5 & - & 4 & - & 1 & - & 11 \\
\hline Morocran & 7 & - & 6 & - & 2 & - & 1 & - & 8 \\
\hline Moroccan & 9 & - & 5 & - & 2 & - & 1 & - & 10 \\
\hline & 2 & - & 4 & - & 2 & - & 1 & - & 10 \\
\hline Moroccan & 2 & - & 4 & - & 2 & - & 1 & - & 8 \\
\hline Turkish & 3 & - & 4 & - & 6 & - & 1 & - & 10 \\
\hline & 3 & - & 4 & - & 6 & - & 1 & - & 10 \\
\hline & 3 & - & 4 & - & 2 & - & 1 & - & 11 \\
\hline Turki & $\{9$ & - & 4 & - & 2 & - & 1 & - & 11 \\
\hline
\end{tabular}

Figure 2 Extended haplotypes in the non-Finnish LPI families. $\mathrm{H}$ aplotypes in lines 1 to 10 from the top are from the five families originating from a small village near $\mathrm{N}$ aples $(*)$. Three of the patients are homozygous to an extended haplotype 6-6-1-12 and one patient has 6-1 haplotype in one of the chromosomes (grey box). Two Italian patients have the haplotype 6-4-13 (D 14S283, TCRA and MYH 7) which is in linkage disequilibrium in the Finnish LPI chromosomes (open box). 
Swedish, Estonian and Lithuanian patients had the same TCRA allele 4 that showed strong linkage disequilibrium in the Finnish LPI chromosomes. Swedish LPI chromosomes also shared D 14S283 allele 6 in linkage disequilibrium with the Finnish LPI chromosomes, possibly reflecting a common origin of the mutation in the Finnish and Swedish patients.

The recognition of locus homogeneity in patients with LPI coming from ethnically different populations now allows linkage-based diagnosis and carrier detection for LPI families with at least one previous affected child. Mutation specific DNA diagnosis of LPI still waits for the cloning of the gene and identification of the disease-causing mutation. Strong linkage disequilibrium found in the Finnish LPI chromosomes with the most tightly linked markers provides a good basis for identification of the LPI gene.

\section{Acknowledgements}

We thank the lysinuric protein intolerance families for their excellent cooperation. We also thank Drs Albers, Bakker, Dianzani, Dionisi Vici, D iR occo, Gustavsson, K ågström, M ancini, Parenti, Parini, Poll-The, R andak, Schweitzer, Strisciuglio and Öunap for providing DNA samples from their patients. The financial support of Telethon-Italy (Grant $\mathrm{E} .652$ ) and by the Ulla $\mathrm{H}$ jelt Fund of the Foundation for Pediatric R esearch, Finland, is especially acknowledged.

\section{References}

1 Simell 0 : Lysinuric protein intolerance and other cationic aminoacidurias. In: Scriver CR, B eaudert A L, Sly W S, Valle $D$ (eds). The Metabolic and Molecular B ases of Inherited Disease. McG raw-Hill: New York, 1995, vol 3, pp 3603-3627.

2 Incerti B, A ndria G, Parenti $G$ et al: Lysinuric protein intolerance: studies on 17 I talian patients. A m J H um G enet 1993; 53 suppl: 908.

3 L auteala $T$, Sistonen $P$, Savontaus $M-L$ et al: Lysinuric protein intolerance ( $\mathrm{LPI}$ ) maps to the long arm of the chromosome 14. A m J H um G enet 1997; 60: 1479-1486.

4 Parenti G, Sebastio G, Strisciuglio P et al: Lysinuric protein intolerance characterized by bone marrow abnormalities and severe clinical course. J Pediatr 1995; 126: 246-251.

5 Kato T, Sano M, Mizutani N: Homocitrullinuria and homoargininuria in lysinuric protein intolerance. J Inherit M etab D is 1989; 12: 157-161.

6 Lathrop GM, Lalouel J M, Julier C, Ott J: Strategies for multilocus linkage analysis in humans. $\mathrm{P}$ roc $\mathrm{N}$ at $\mathrm{A}$ cad $\mathrm{Sci}$ USA 1984; 81: 3443-3446.

7 K ruglyak L, D aly M, R eeve-D aly M , L ander E : Parametric and non-parametric linkage analysis: a unified multipoint approach. A m J H um G enet 1996; 58: 1347-1363.

$8 \mathrm{D} \mathrm{ib} \mathrm{C}$, Faure S, Fizames $C$ et al: A comprehensive genetic map of the human genome based on 5264 microsatellites. N ature 1996; 380: 152-154.

$9 \mathrm{Ott} \mathrm{J}$ : A nalysis of $\mathrm{H}$ uman $\mathrm{G}$ enetic L inkage. John $\mathrm{H}$ opkins U niversity Press: Baltimore, 1991. 